\title{
Management of visceral arterial pseudoaneurysms in patients with acute and chronic pancreatitis: a retrospective study from South Indian tertiary care centre
}

\author{
Afroj Ismail Bagwan, Kalyansundarbharathi Chidambaram, Sugaprakash Sankareswaran, \\ Prabhakaran Raju, Sugumar Chidambaranathan, Naganath Babu Obla Lakshamanamoorthy*
}

Institute of Surgical Gastroenterology, Madras Medical College, Chennai, Tamil Nadu, India

Received: 28 July 2021

Revised: 03 September 2021

Accepted: 04 September 2021

\author{
*Correspondence: \\ Dr. Naganath Babu Obla Lakshamanamoorthy, \\ E-mail: naganathbabu@gmail.com
}

Copyright: () the author(s), publisher and licensee Medip Academy. This is an open-access article distributed under the terms of the Creative Commons Attribution Non-Commercial License, which permits unrestricted non-commercial use, distribution, and reproduction in any medium, provided the original work is properly cited.

\begin{abstract}
Background: Visceral artery pseudoaneurysms (VAP) are defined as those affecting celiac, superior or inferior mesenteric arteries and their branches. In this study, role of various therapeutic modalities in the management of VAP caused by acute and chronic pancreatitis were analysed which can influence choice of treatment for a given patient. Methods: The study was conducted in institute of surgical gastroenterology, Madras medical college and Rajiv Gandhi government general hospital Chennai, based on retrospective analysis of 41 patients diagnosed with VAP caused by acute and chronic pancreatitis admitted between the periods of September 2014 and January 2020. The medical records of all patients were retrieved and descriptive statistical analyses was carried out regarding various details including demographics, presentation, management and complications.

Results: This study includes 41 patients with mean age of $39.73 \pm 10.54$ (SD) years and $40(97.56 \%)$ of them were males. Fifteen patients $(36.59 \%)$ had acute pancreatitis and 26 patients $(63.41 \%)$ had chronic pancreatitis. Pseudocysts were found in $25(60.98 \%)$ patients. Pseudoaneurysm arose most commonly from splenic artery $(\mathrm{n}=32$; $78.04 \%)$. The most common symptom was abdominal pain $(n=40)$ followed by gastrointestinal bleeding $(n=28)$. Sixteen patients $(39 \%)$ received primary radiological reintervention $(n=16)$. Twenty-five patients $(60.98 \%)$ underwent primary surgical treatment $(n=25)$. Rebleeding was seen in 3 patients $(7.32 \%)$. Twenty-three patients $(56.1 \%)$ developed complications. Mortality rate was 5/41 (12.2\%).

Conclusions: Pseudoaneurysms are fatal complications of pancreatitis. Angiographic embolization, when available, is the initial treatment of choice in hemodynamically stable patients. Surgery in experienced hands will still remain main modality in treating these patients in centres that lack a full-fledged angiographic facility with acceptable outcomes.
\end{abstract}

Keywords: Pseudoaneurysm, Visceral artery pseudoaneurysm, Pancreatitis

\section{INTRODUCTION}

Pancreatitis is an inflammatory pathology that affects the glandular organ and is associated with a variety of local and systemic complications. Peripancreatic pseudoaneurysm is a rare vascular complication of pancreatitis caused by either direct erosion of an arterial wall by a pseudocyst or necrotic collection or, more commonly, enzymatic breakdown of the arterial wall by pancreatic secretions. However, it may also happen after pancreatic or gastric surgery or trauma. ${ }^{1}$ Pseudoaneurysms most commonly affect the splenic artery, followed by gastroduodenal, pancreaticoduodenal, gastric and hepatic arteries.,3 Regardless of their size, VAP present with a significant risk of spontaneous rupture and fatal haemorrhage, with a reported mortality 
rate approaching $100 \%$ if left untreated, and even with aggressive treatment the mortality is between 18 and $29 \% .^{2,4,5}$ While management of other local complications like pseudocyst or walled off necrotic collections are fairly standardised with predictable outcomes, patients presenting with VAPs pose a therapeutic challenge in choosing the right pathway of management to address both the pseudoaneurysm and other associated manifestations of pancreatitis due to its rarity and requirement of surgical expertise and intensive resources. ${ }^{6-8}$ There is also scarcity of studies that emphasized in detail on the management of pancreatitis associated pseudoaneurysms. Hence, this retrospective study was conducted to determine the various management techniques of pseudoaneurysms caused by acute and chronic pancreatitis and to determine the associated complications

\section{METHODS}

\section{Patients}

The study was conducted in institute of surgical gastroenterology, Madras medical college and Rajiv Gandhi government general hospital, Chennai, based on retrospective analysis of prospectively maintained institutional database of 41 patients diagnosed with VAPs caused by acute and chronic pancreatitis admitted between the periods of September 2014 and January 2020. The medical records of this patients were retrieved and various details including demographics, presentation, management and complications were determined.

\section{Inclusion criteria}

All visceral artery pseudoaneurysm patients with underlying acute and chronic pancreatitis who presented to our centre and received surgical or radiological interventions are included in the study.

\section{Exclusion criteria}

Patients who developed VAPs due to other causes such as trauma, cancer, infection, vascular interventions, or postsurgery are not included in the study.

\section{Diagnosis}

Pancreatitis patients presenting with gastrointestinal bleeding were subjected to oesophagogastroduodenoscopy (OGD) to rule out variceal and non-variceal causes of luminal bleeding and demonstrate blood in second part of duodenum exuding from ampullary opening in case of hemo-succus pancreaticus. Ultrasonography with Doppler study was done in all patients as a screening tool. Contrast enhanced multidetector CT scan was performed which reveals the presence and location of pseudoaneurysm, and presence of bleeding into local peripancreatic collection or into the peritoneum. MRI abdomen was done in patients who were not suitable for CECT due to deranged renal parameters.

\section{Management}

If no other surgical intervention was planned, asymptomatic pseudoaneurysms discovered incidentally during routine imaging were subjected to angiography and embolisation. In patients who needed surgery for other reasons such as the presence of a pseudocyst or underlying chronic pancreatitis, pseudoaneurysms were dealt with in the same surgical exploration. Patients presenting with bleeding pseudoaneurysm were treated according to the hemodynamic status and availability of angiographic facility. Patients with bleeding VAPs who presented with hemodynamic instability were resuscitated and, if stabilised, they were subjected to angiographic studies and angioembolisation and, if could not be stabilised, they were considered for emergency surgery. Surgery was also considered in whom either angioembolisation was not possible or not successful in controlling bleeding.

\section{Statistical analysis}

Descriptive statistical analyses were carried out in the present study. Results on continuous measurements were presented on mean $\pm \mathrm{SD}$ and results on categorical measurement were presented in number (\%). Microsoft word and excel were used to generate tables.

\section{RESULTS}

This study includes 41 patients which comprises of 40 males $(97.56 \%)$ and 1 female. Mean age of patients was $39.73 \pm 10.54$ (SD) years (25-73 years). Fifteen patients $(36.59 \%)$ had acute pancreatitis and 26 patients $(63.41 \%)$ had chronic pancreatitis. Alcohol was the causative factor in 37 patients $(90.24 \%)$. Three patients $(7.32 \%)$ had tropical chronic pancreatitis and one patient $(2.44 \%)$, who was a female, had acute biliary pancreatitis (Table $1)$.

Pseudoaneurysm arose from splenic artery in 32 (78.04\%) patients (29 in mid or distal part and 3 in proximal part of splenic artery) and gastroduodenal artery (GDA) in $4(9.76 \%)$ patients. One patient each had pseudoaneurysm involving common hepatic artery (CHA) $(n=1)$, superior pancreatoduodenal artery (SPDA) $(\mathrm{n}=1)$ and inferior pancreatoduodenal artery (IPDA) $(n=1)$. Two patients $(4.88 \%)$ had pseudoaneurysms arising from multiple arteries, including the splenic artery and gastrodoudenal artery (GDA) in one patient and the left gastric artery (LGA) and left hepatic artery (LHA) in another patient. Mean diameter of pseudoaneurysm was $3.97 \pm 1.18 \mathrm{~cm}(1-5.6 \mathrm{~cm})$. Pseudocysts were found in 25 patients $(60.98 \%) \quad(n=25)$. Most common presenting symptoms was pain in abdomen $(n=40)(97.56 \%)$ followed by gastrointestinal bleed $(\mathrm{n}=28) \quad(68.29 \%)$ (Table 2). 
Table 1: Patient characteristics and clinical parameters.

\begin{tabular}{|llll|}
\hline Characteristics & Total $(\mathbf{n = 4 1})(\%)$ & $\mathbf{A P}(\mathbf{n = 1 5}),(\%)$ & $\mathbf{C P}(\mathbf{n = 2 6}),(\%)$ \\
\hline Age (years) (mean) & $39.73 \pm 10.41$ & $38.8 \pm 9.05$ & $40.27 \pm 11.44$ \\
\hline Sex ratio (M:F) & $41: 1$ & $14: 1$ & $26: 0$ \\
\hline Social habits & & & \\
\hline Smoking and alcohol & $29(71.7)$ & $10(66.7)$ & $19(73.08)$ \\
\hline Alcohol only & $8(19.5)$ & $4(26.7)$ & $4(15.38)$ \\
\hline None & $4(9.76)$ & $1(6.7)$ & $3(11.54)$ \\
\hline Comorbidities & & & \\
\hline 0 & $33(80.49)$ & $13(86.6)$ & $20(76.92)$ \\
\hline 1 & $8(19.51)$ & $2(13.3)$ & $6(23.08)$ \\
\hline$\geq 2$ & 0 & 0 & 0 \\
\hline Past intervention & & & \\
\hline None & $27(65.58)$ & $10(66.7)$ & $17(65.38)$ \\
\hline PCD & $4(9.5)$ & $1(6.67)$ & $3(11.54)$ \\
\hline PD stenting & $2(4.88)$ & $1(6.67)$ & $1(3.85)$ \\
\hline Angioembolisation & $1(2.44)$ & $1(6.67)$ & 0 \\
\hline Surgery & $4(9.5)$ & $1(6.67)$ & $3(11.54)$ \\
\hline Cystogastrostomy/ cystojejunostomy & $2(4.88)$ & $1(6.67)$ & $1(3.85)$ \\
\hline Laparotomy unrelated etiology & $2(4.88)$ & 0 & $2(7.69)$ \\
\hline Other surgeries & $3(7.1)$ & $1(6.67)$ & $2(7.69)$ \\
\hline
\end{tabular}

Table 2: Artery involved with pseudoaneurysms.

\begin{tabular}{|llll|}
\hline Characteristics & Total $(\mathbf{n = 4 1}),(\%)$ & AP $(\mathbf{n = 1 5}),(\%)$ & $\mathbf{C P}(\mathbf{n = 2 6}),(\%)$ \\
\hline Artery involved & & & $18(69.23)$ \\
\hline Splenic & $32(78.05)$ & $14(93.3)$ & $4(15.38)$ \\
\hline GDA & $4(9.76)$ & 0 & $1(3.85)$ \\
\hline CHA & $1(2.44)$ & 0 & $1(3.85)$ \\
\hline SPDA & $1(2.44)$ & 0 & 0 \\
\hline IPDA & $1(2.44)$ & $1(6.67)$ & $1(3.85)$ \\
\hline SPLENIC + GDA & $1(2.44)$ & 0 & $1(3.85)$ \\
\hline LGA+LHA & $1(2.44)$ & 0 & $4.07 \pm 1.22$ \\
\hline Size of aneurysm (mean) $(\mathrm{cm})$ & $3.97 \pm 1.18$ & $3.78 \pm 1.15$ & $16(61.54)$ \\
\hline Associated pseudocyst & & & $10(38.46)$ \\
\hline Present & $25(60.98)$ & $9(60)$ & $1(6.25)$ \\
\hline Absent & $16(39.02)$ & $6(40)$ & $3(12.5)$ \\
\hline Gastrointestinal bleeding at presentation & & $11(68.8)$ \\
\hline Hematemesis alone & $2(7.14)$ & $1(8.33)$ & $1(6.25)$ \\
\hline Melena alone & $5(17.86)$ & $2(16.7)$ & $5(41.6)$ \\
\hline Hematemesis and melena & $16(57.1)$ & $4(13.3)$ & \\
\hline Hematochezia alone & $5(17.86)$ & & \\
\hline
\end{tabular}

Ultrasonography with Doppler study was performed as a screening tool in all patients. Esophagogastroduodenoscopy (OGD) was done in all patients to rule out other causes of bleeding, it showed blood in second part of duodenum exuding from ampullary opening in 4 patients only. Cross-sectional CECT angiogram was performed on 37 patients and it revealed the presence of a pseudoaneurysm in 35 of them (94.59\%). Remaining 4 patients in whom CT scan could not be done due to deranged renal parameters, VAP was demonstrated in MRI or ultrasound Doppler study. Pseudoaneurysm was identified in all patients who underwent Angiography $(\mathrm{n}=16)(100 \%)$ (Table 3).
Table 3: Diagnosis of pseudoaneurysms.

\begin{tabular}{|ll|}
\hline Investigations & $\begin{array}{l}\text { Number diagnosed/number of } \\
\text { patients studied }(\%)\end{array}$ \\
\hline Angiography & $16 / 16(100)$ \\
\hline CECT & $35 / 37(94.59)$ \\
\hline MRI & $2 / 4(50)$ \\
\hline Doppler & $8 / 41(19.5)$ \\
\hline OGD & $4 / 41(9.76)$ \\
\hline
\end{tabular}

Twenty-eight out of $41(68.29 \%)$ patients presented with signs of hypovolemic shock $(n=28)$ were resuscitated initially, out of them 12 patients were stabilised and subjected to angiography and angioembolisation. 
Remaining 16 patients who couldn't be stabilised with resuscitation alone, were taken up for surgical intervention, of whom bleeding was arrested in 15 patients and in 1 patient, it was a non-therapeutic laparotomy due to dense adhesions and frozen abdomen who was later treated with angioembolisation for rebleeding. Thirteen patients out of $41(31.71 \%)$ were hemodynamically stable at presentation $(n=13)$. Of these 13 patients, 9 patients had associated underlying pathologies like pseudocysts, chronic pancreatitis predominantly involving tail of the pancreas or the location of pseudoaneurysm in the distal splenic artery, which necessitated surgery and pseudoaneurysm was dealt with in the same surgical exploration in such patients (Figure 1 and 2). Remaining 4 patients, who were hemodynamically stable at presentation and had no surgical indications otherwise, underwent primary angioembolisation.

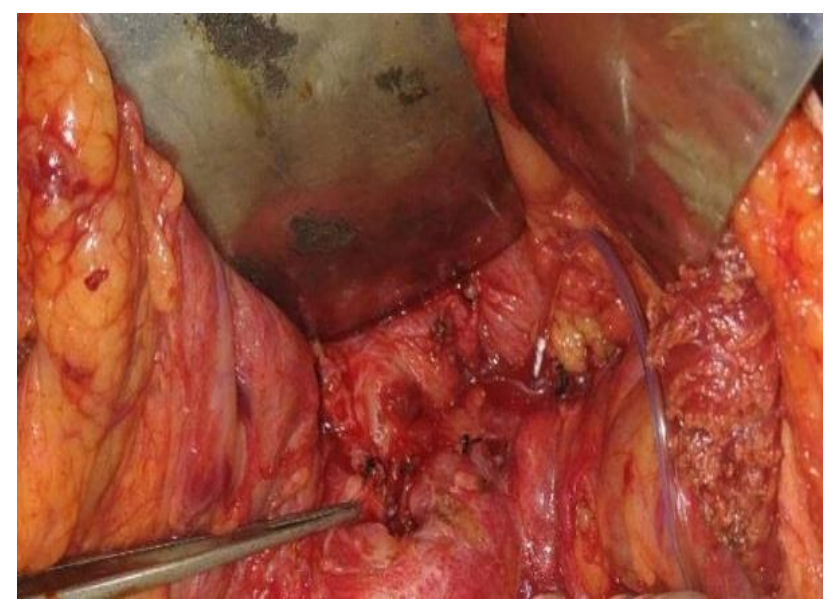

Figure 1: Intra-operative picture of splenic artery pseudoaneurysm in a patient with chronic pancreatitis.

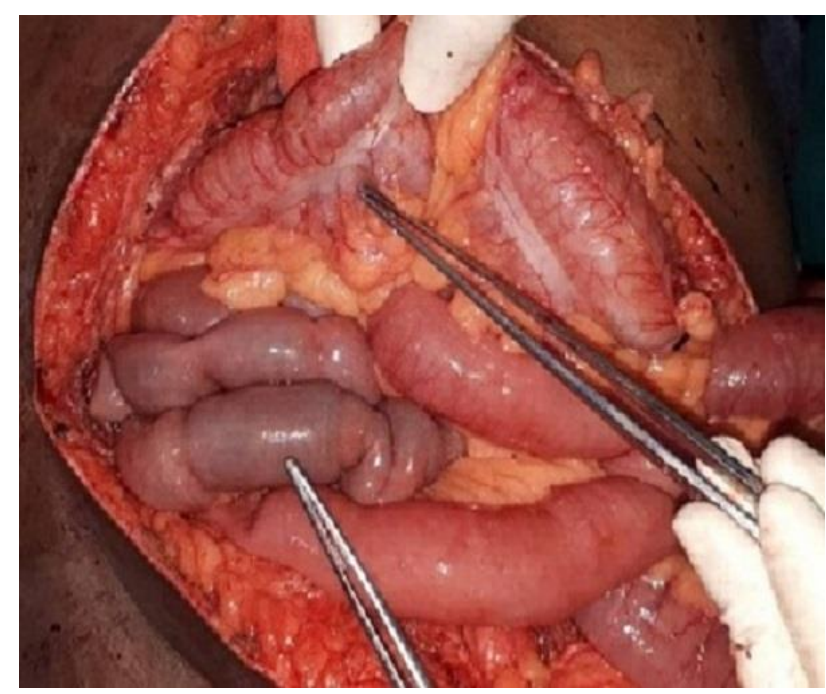

Figure 2: Intra-operative finding of intra-luminal bleeding in patients with bleeding due to splenic artery pseudoaneurysm due to pancreatitis.
Sixteen out of $41(39 \%)$ patients received primary radiological treatment $(n=16)$, of them 11 had coil angioembolisation (26.83\%), 2 patients had coil embolization plus thrombin injection $(4.88 \%)$ and 1 patient each had gel foam embolization, thrombin injection and stent placement (2.44\%) (Figure 3 and 4). Twenty-five patients out of $41(60.98 \%)$ underwent primary surgical interventions $(n=25)$. Distal pancreatosplenectomy (DPS) $(n=20)$ was the most commonly performed primary surgical intervention either alone ( 7 out of 25) or in combination with other procedures (13 out of 25) (Table 4).

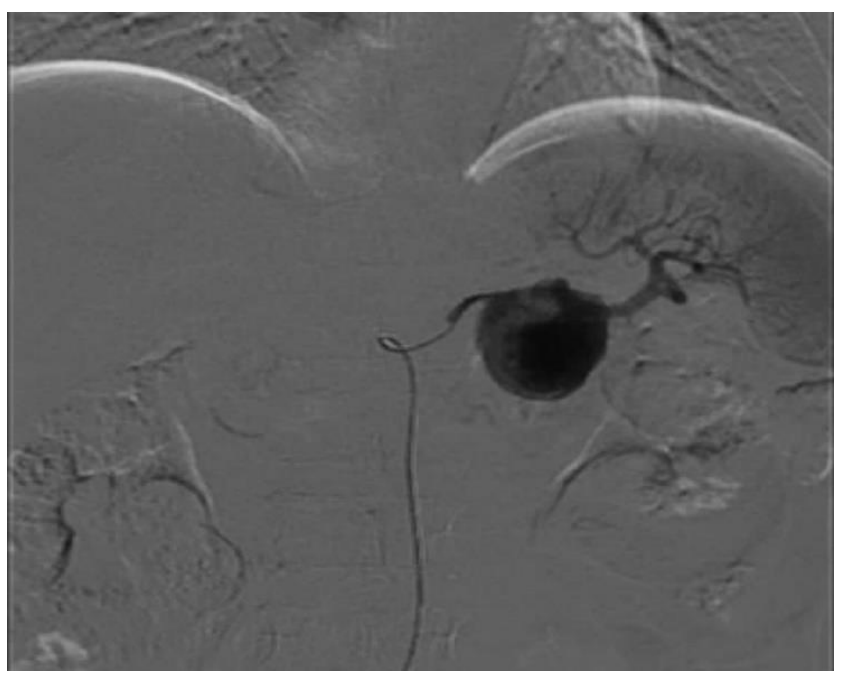

Figure 3: A bleeding splenic artery pseudoaneurysm due to pancreatitis was managed by primary angioembolisation.

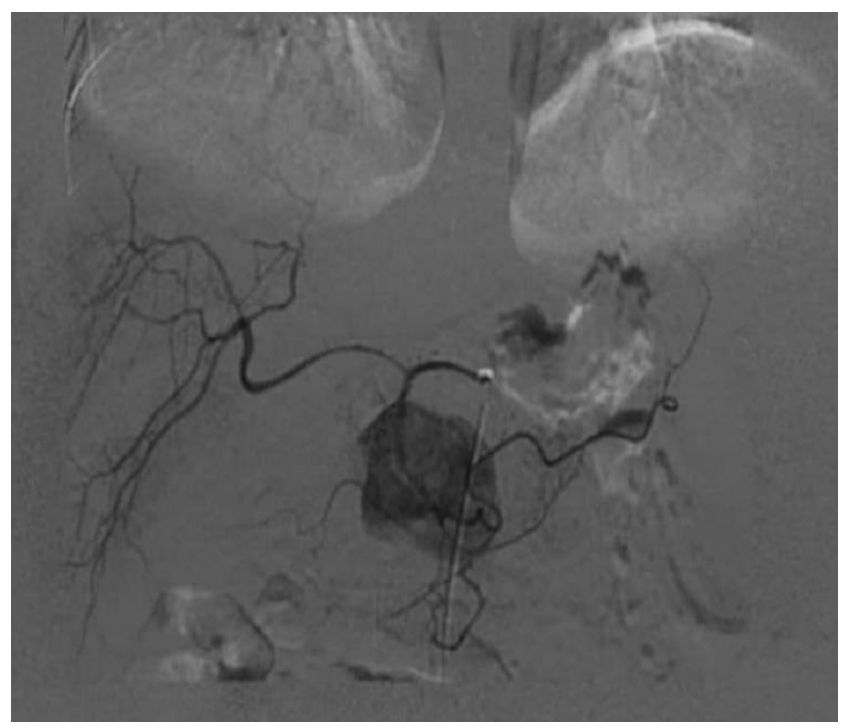

Figure 4: A bleeding gastroduodenal artery pseudoaneurysm due to pancreatitis was managed by primary angioembolisation.

Twenty-three patients $(56.1 \%)$ had complications $(n=23)$. Of these, 17 patients had received primary surgical intervention and 6 patients had received primary 
radiological intervention. When a patient had multiple complications, highest grade of complication is reported according to Clavien Dindo grading, which includes 15 patients $(36.58 \%$ ) with minor (grade 1 or 2) and 8 patients $(19.51 \%)$ with major complications (grade 3 or more). Total 25 complications were reported which includes 13 local complications and 12 systemic complications. The organ failure was seen in 13 patients (31.7\%) which was transient in 8 patients and remained persistent in 5 patients. Mortality rate was $5 / 41(12.2 \%)$ in our series of whom two had acute pancreatitis and three patients had chronic pancreatitis. Four of the 5 deaths occurred in patients presenting with hematochezia. Four out of 5 patients who expired had accompanying pseudocyst and one patient had acute necrotic collection. Of the 5 patients who expired two had primary surgical intervention and three patients had primary coil angioembolisation. Four out of 5 patients who expired had splenic artery pseudoaneurysm and one patient had common hepatic artery pseudoaneurysm. Of the three rebleeding patients in our series one expired (Table 5).

Table 4: Management of patients with pseudoaneurysms.

\begin{tabular}{|c|c|c|c|}
\hline Managements & $\begin{array}{l}\text { Total } \\
(n=41) \\
(\%)\end{array}$ & $\begin{array}{l}\mathbf{A P} \\
(\mathbf{n}=15) \\
(\%)\end{array}$ & $\begin{array}{l}\mathrm{CP} \\
(\mathrm{n}=26) \\
(\%)\end{array}$ \\
\hline Angioembolisation & $\begin{array}{l}16 \\
(39.02)\end{array}$ & $\begin{array}{l}4 \\
(26.67)\end{array}$ & $\begin{array}{l}12 \\
(46.15)\end{array}$ \\
\hline Coil & $\begin{array}{l}11 \\
(28.6)\end{array}$ & $\begin{array}{l}3 \\
(20)\end{array}$ & $\begin{array}{l}8 \\
(30.77)\end{array}$ \\
\hline Thrombin & $1(2.44)$ & 0 & $1(3.85)$ \\
\hline Gel foam & $1(2.44)$ & 0 & $1(3.85)$ \\
\hline Stent & $1(2.44)$ & $1(6.67)$ & 0 \\
\hline Thrombin with coil & $2(4.88)$ & 0 & $2(7.7)$ \\
\hline Surgical procedures & $\begin{array}{l}25 \\
(60.98)\end{array}$ & $\begin{array}{l}11 \\
(73.33)\end{array}$ & $\begin{array}{l}14 \\
(53.85)\end{array}$ \\
\hline DPS & $\begin{array}{l}7 \\
(17.07)\end{array}$ & $\begin{array}{l}4 \\
(26.67)\end{array}$ & $\begin{array}{l}3 \\
(11.54)\end{array}$ \\
\hline $\begin{array}{l}\text { DPS + gastric } \\
\text { resection }\end{array}$ & $\begin{array}{l}6 \\
(14.63)\end{array}$ & $\begin{array}{l}2 \\
(13.33)\end{array}$ & $\begin{array}{l}4 \\
(15.38)\end{array}$ \\
\hline $\begin{array}{l}\text { DPS + colonic } \\
\text { resection }\end{array}$ & $\begin{array}{l}3 \\
(7.32)\end{array}$ & $\begin{array}{l}2 \\
(13.33)\end{array}$ & $\begin{array}{l}1 \\
(3.85)\end{array}$ \\
\hline $\begin{array}{l}\text { DPS + } \\
\text { Cholecystectomy }\end{array}$ & $1(2.44)$ & $1(6.67)$ & 0 \\
\hline DPS + Frey's + CDJ & $1(2.44)$ & 0 & $1(3.85)$ \\
\hline DPS + LPJ & $1(2.44)$ & 0 & $1(3.85)$ \\
\hline $\begin{array}{l}\text { DPS + ligation of } \\
\text { pseudoaneurysm }\end{array}$ & $1(2.44)$ & $1(6.67)$ & 0 \\
\hline $\begin{array}{l}\text { Ligation of } \\
\text { pseudoaneurysm } \\
\text { alone }\end{array}$ & $2(4.88)$ & $1(6.67)$ & $1(3.85)$ \\
\hline Splenectomy + Frey's & $1(2.44)$ & 0 & $1(3.85)$ \\
\hline $\begin{array}{l}\text { Cystogastrostomy + } \\
\text { Ligation of PSA }\end{array}$ & $1(2.44)$ & 0 & $1(3.85)$ \\
\hline $\begin{array}{l}\text { Non-therapeutic } \\
\text { laparotomy }\end{array}$ & $1(2.44)$ & 0 & $1(3.85)$ \\
\hline
\end{tabular}

Overall, 11 patients (26.83\%) needed reinterventions $(n=11)$ consisting of 8 patients with primary radiological intervention and 3 patients with primary surgical intervention. Three patients $(7.32 \%)$ had rebleeding after primary intervention, 1 each after coil embolization, gel foam embolization and surgery and they were dealt with by DPS, DPS with colonic resection, and coil embolization plus thrombin injection respectively (Table $6)$.

Table 5: Complications associated with the management.

\begin{tabular}{|c|c|c|c|}
\hline Characteristics & $\begin{array}{l}\text { Total } \\
(n=41) \\
(\%)\end{array}$ & $\begin{array}{l}\mathbf{A P} \\
(n=15) \\
(\%)\end{array}$ & $\begin{array}{l}\mathrm{CP} \\
(\mathrm{n}=26) \\
(\%)\end{array}$ \\
\hline \multicolumn{4}{|l|}{ Local complications } \\
\hline Pancreatic fistula & $6(14.63)$ & $3(20)$ & $3(11.54)$ \\
\hline $\mathrm{A} / \mathrm{B}$ & $5(11.9)$ & $2(13.33)$ & $3(11.54)$ \\
\hline $\mathrm{C}$ & $1(2.44)$ & $1(6.67)$ & 0 \\
\hline Wound infection & $5(12.2)$ & $2(13.33)$ & $3(11.54)$ \\
\hline Anastomotic leak & $1(2.44)$ & $1(6.67)$ & 0 \\
\hline \multicolumn{4}{|c|}{ Systemic complications } \\
\hline $\begin{array}{l}\text { Respiratory } \\
\text { infections }\end{array}$ & $4(9.76)$ & $1(6.67)$ & $3(11.54)$ \\
\hline MODS & $5(12.2)$ & $2(13.33)$ & $3(11.54)$ \\
\hline $\begin{array}{l}\text { Urinary tract } \\
\text { infection }\end{array}$ & $1(2.44)$ & $1(6.67)$ & 0 \\
\hline $\begin{array}{l}\text { Alcohol withdrawal } \\
\text { delirium }\end{array}$ & $1(2.44)$ & 0 & $1(3.85)$ \\
\hline Thrombocytosis & $1(2.44)$ & $1(6.67)$ & 0 \\
\hline Bedsore & $1(2.44)$ & 0 & $1(3.85)$ \\
\hline Rebleeding & $3(7.32)$ & 0 & $3(11.54)$ \\
\hline \multicolumn{4}{|l|}{ Organ failure } \\
\hline No & $\begin{array}{l}28 \\
(68.29)\end{array}$ & $\begin{array}{l}10 \\
(66.67)\end{array}$ & $\begin{array}{l}18 \\
(69.23)\end{array}$ \\
\hline Transient & $8(19.51)$ & $3(20)$ & $5(19.23)$ \\
\hline Persistent & $5(12.2)$ & $2(13.33)$ & $3(11.54)$ \\
\hline Mortality & $5(12.2)$ & $2(13.33)$ & $3(11.54)$ \\
\hline
\end{tabular}

Table 6: Reinterventions.

\begin{tabular}{|llll|}
\hline $\begin{array}{l}\text { Indications for } \\
\text { reinterventions }\end{array}$ & $\begin{array}{l}\text { Total, } \\
(\mathbf{n}=\mathbf{1 1})\end{array}$ & $\begin{array}{l}\text { After } \\
\text { radiological } \\
\text { intervention } \\
(\mathbf{n = 8})\end{array}$ & $\begin{array}{l}\text { After } \\
\text { surgical } \\
\text { inter- } \\
\text { vention, } \\
(\mathbf{n}=\mathbf{3})\end{array}$ \\
\hline $\begin{array}{l}\text { Rebleeding } \\
\begin{array}{l}\text { Intra-abdominal } \\
\text { collection }\end{array}\end{array}$ & 3 & 2 & 1 \\
\hline $\begin{array}{l}\text { Grade C } \\
\text { pancreatic fistula }\end{array}$ & 1 & 2 & 0 \\
\hline $\begin{array}{l}\text { Anastomotic leak } \\
\text { Definitive surgery } \\
\text { after primary } \\
\text { angioembolisation }\end{array}$ & 1 & 0 & 1 \\
\hline $\begin{array}{l}\text { Repeat } \\
\text { angioembolisation }\end{array}$ & 2 & 2 & 1 \\
\hline
\end{tabular}




\section{DISCUSSION}

VAP are defined as those affecting the celiac, superior or inferior mesenteric arteries and their branches. ${ }^{9}$ Unlike a true aneurysm which contains all 3 layers of an artery but thinned and dilated, pseudoaneurysm lack normal vessel architecture and forms as a result of a focal defect in arterial wall leading to formation of a periarterial hematoma contained by surrounding fibrous tissue. ${ }^{10}$ This explains the increased risk of rupture in pseudoaneurysms compared to true aneurysms and hence all false aneurysms are typically treated when diagnosed. The common causes for visceral artery pseudoaneurysm are pancreatitis, infection, vascular intervention, surgery, and blunt trauma. ${ }^{11}$ Reports on pancreatitis complicated with pseudoaneurysm bleeding are mainly retrospective, and most are from a single institute or limited case reports. Hence, this retrospective study was conducted to determine various management techniques of pseudoaneurysms caused by acute and chronic pancreatitis along with the diagnosis, demography and the associated complications.

Studies by Bhasin et al and Kulkarni et al reported that pancreatitis related VAP predominantly affects male population. ${ }^{5,12}$ In study the mean age of the patients was $39.73 \pm 10.54$ (SD) years, predominantly consisting of male patients (40 out of 41-97.56\%). The alcohol intake (90.24\%) was the major cause of pancreatitis and most patients had chronic form of pancreatitis (63.41\%). The occurrence of vascular complications in form of pseudoaneurysm of visceral arteries has been reported to range from $1.2-14 \%$ with a higher incidence in chronic pancreatitis $(7-10 \%)$ than in acute pancreatitis $(1-6 \%)$ patients. ${ }^{12-14}$

Pseudocysts or necrotic collection accelerate the formation of peripancreatic pseudoaneurysm though reports suggest that it can form even in the absence of local collections. The enzymatic destruction of pancreatic and extra-pancreatic tissue occurs in necrotizing pancreatitis, which leads to the destruction of blood vessels and formation of pseudoaneurysms. ${ }^{15,16}$ Carr et al determined in their study that the management of pancreatic pseudocyst associated pseudoaneurysms is more challenging problem and is associated with high death rate. $^{7}$ Operation and angiographic embolization play complementary management roles. ${ }^{7}$ Elton et al described successful treatment of 3 patients having pseudocysts with pseudoaneurysms using combination of embolization with endoscopic trans-papillary drainage of communicating pseudocyst. ${ }^{17}$ Bhasin et al in their study treated patients with percutaneous thrombin injection, digital subtraction angiography and angioembolisation and surgery. ${ }^{5}$ Most common treatment done in our study was surgery and angioembolisation.

Over the past decade, angiography has improved the diagnostic accuracy for visceral pseudoaneurysms. ${ }^{18-20}$ In our study, conventional Angiography demonstrated the pseudoaneurysm in all patients who underwent the study (100\% in 16 patients) and also provided a therapeutic opportunity with selective embolization with various agents like coils, stents, thrombin injection and gel foam. Boudghe'ne et al reported the $96 \%$ sensitivity in the largest multicentre series of 93 patients using a response questionnaire to pooled data. ${ }^{21}$ CECT angiogram of abdomen was useful in diagnosing a pseudoaneurysm in 35 of 37 (94.59\%) patients who undergone the investigation. Due to its non-invasive nature and rapidity in acquisition of high-quality cross-sectional imaging, CECT angiogram can be used as the initial imaging modality of choice in patients presenting with bleeding and pancreatitis. Many studies have also confirmed this finding. ${ }^{22,23}$ Doppler USG though readily available in secondary care facilities was not sensitive enough (detected presence of pseudoaneurysm in eight out of forty-one patients-19.5\%) in diagnosis of pseudoaneurysms. MRI without contrast is low in sensitivity for smaller pseudoaneurysms and generally not performed due to its higher cost and longer time of study undesirable in emergency bleeding condition. ${ }^{22,23}$ However, in patients with contraindications for both CT and MR imaging, USG may be useful for demonstrating the presence of non-liquefied material within a collection. ${ }^{23,24}$

In the study by De Perrot et al, Carr et al and Hsu et al it was suggested that the angiographic embolization is recommended as the initial therapy for hemodynamically stable patients. ${ }^{7,25,26}$ Surgery should be reserved for actively bleeding, hemodynamically unstable patients; for failed embolization; and for other associated secondary complications such as infection or extrinsic compression. In the present study, most common location of VAPs was splenic artery in 32 patients ( 29 in mid or distal part and 3 in proximal part of splenic artery). The 16 patients (39\%) underwent angioembolisation with Coil embolization and thrombin being the most common treatment. 25 (60.98\%) patients underwent surgery. The 20 of the patients who underwent surgery had DPS (80\%) since most common location of pseudoaneurysm is mid or distal portion of splenic artery. Operation and percutaneous angio embolization played complementary management roles.

This study has some limitations. This is a retrospective study. The urgent condition of pancreatitis associated pseudoaneurysm bleeding complicates the management, and thus prospective randomized trials is not feasible. This study was a single centre experience; thus, the study cannot be extrapolated to all situations and centres. However, our study contributed significantly to the existing literature in the light of management of pancreatic pseudoaneurysm done by inter disciplinary coordination and surgical expertise. Arterial embolization or surgical intervention is the current management techniques in pancreatitis associated visceral artery pseudoaneurysms. 


\section{CONCLUSION}

Pseudoaneurysms are rare complications of pancreatitis which may present variably between asymptomatic to fatal with massive haemorrhage into the bowel, into associated peripancreatic collections or into peritoneal cavity. Angiographic embolization, when available is the initial treatment of choice in hemodynamically stable patients due to its low associated morbidity and a modest rate of rebleed while surgery is indicated in angiographic failures and hemodynamically unstable patients with more morbidity but lesser rate of rebleed. If a pseudoaneurysm is located over the tail of the pancreas, resection is the preferred procedure, whereas for pseudoaneurysm situated near head or body of the pancreas relatively conservative surgical procedures are recommended. Surgery in experienced hands will still remain the main modality in treating these patients in centres that lack a full-fledged angiographic facility with acceptable outcomes

\section{ACKNOWLEDGEMENTS}

Author would like to thanks the help from department of interventional radiology, Madras medical college, Rajiv Gandhi government general hospital, Chennai, India in publication of this article.

Funding: No funding sources

Conflict of interest: None declared

Ethical approval: The study was approved by the Institutional Ethics Committee

\section{REFERENCES}

1. Gurala D, Polavarapu AD, Idiculla PS, Daoud M, Gumaste V. Pancreatic Pseudoaneurysm from a Gastroduodenal Artery. Case Rep Gastroenterol. 2019;13(3):450-5.

2. Zabicki B, Limphaibool N, Holstad MJV, Juszkat R. Endovascular management of pancreatitis-related pseudoaneurysms: A review of techniques. Plos one. 2018;13(1):e0191998.

3. Tessier DJ, Stone WM, Fowl RJ, Abbas MA, Andrews JC, Bower TC et al. Clinical features and management of splenic artery pseudoaneurysm: case series and cumulative review of literature. J Vasc Surg. 2003;38(5):969-74.

4. Saad NEA, Saad WEA, Davies MG, Waldman DL, Fultz PJ, Rubens DJ. Pseudoaneurysms and the Role of Minimally Invasive Techniques in Their Management. Radio Graphics. 2005:S173-89.

5. Bhasin DK, Rana SS, Sharma V, Rao C, Gupta V, Gupta $R$ et al. Non-surgical management of pancreatic pseudocysts associated with arterial pseudoaneurysm. Pancreatology. 2013;13(3):250-3.

6. Cunha EF de C, Rocha M de S, Pereira FP, Blasbalg $\mathrm{R}$, Baroni RH. Walled-off pancreatic necrosis and other current concepts in the radiological assessment of acute pancreatitis. Radiol Bras. 2014;47(3):16575.

7. Carr JA, Cho J-S, Shepard AD, Nypaver TJ, Reddy DJ. Visceral pseudoaneurysms due to pancreatic pseudocysts: Rare but lethal complications of pancreatitis. J Vasc Surg. 2000;32(4):722-30.

8. Chiang KC, Chen TH, Hsu JT. Management of chronic pancreatitis complicated with a bleeding pseudoaneurysm. World J Gastroenterol WJG. 2014;20(43):16132-7.

9. Vittoria De Martini I, Pfammatter T, Puippe G, Clavien P-A, Alkadhi H. Frequency and causes of delayed diagnosis of visceral artery pseudoaneurysms with CT: Lessons learned. Eur J Radiol Open. 2020;7:100221.

10. Rivera PA, Dattilo JB. Pseudoaneurysm. In: Stat Pearls. Treasure Island (FL): Stat Pearls Publishing. 2021. Available from: http://www.ncbi.nlm.nih.gov/books/NBK542244/. Accessed on 10 March 2021.

11. Kuppusamy S, Krishnamachari S, Satheesh S, Nelamangala Ramakrishnaiah V. Visceral artery pseudoaneurysm: A report of three cases. Int $\mathbf{J}$ Adv Med Health Res. 2015;2(2):126.

12. Kulkarni CB, Moorthy S, Pullara SK, Prabhu NK, Kannan RR, Nazar and PK. Endovascular management of pancreatitis related pseudoaneurysms? A single center experience. 2014;3(1):46-53.

13. Flati G, Andrén-Sandberg $\AA$, La Pinta M, Porowska B, Carboni M. Potentially Fatal Bleeding in Acute Pancreatitis: Pathophysiology, Prevention, and Treatment. Pancreas. 2003;26(1):8-14.

14. Sharma PK, Madan K, Garg PK. Hemorrhage in Acute Pancreatitis: Should Gastrointestinal Bleeding Be Considered an Organ Failure? Pancreas. 2008;36(2):141-5.

15. Rashid MU, Hussain I, Jehanzeb S, Ullah W, Ali S, Jain AG et al. Pancreatic necrosis: Complications and changing trend of treatment. World $\mathrm{J}$ Gastrointest Surg. 2019;11(4):198-217.

16. Gurusamy KS, Pallari E, Hawkins N, Pereira SP, Davidson BR. Management strategies for pancreatic pseudocysts. Cochrane Database Syst Rev. 2016;2016(4):CD011392.

17. Elton E, Howell DA, Amberson SM, Dykes TA. Combined angiographic and endoscopic management of bleeding pancreatic pseudoaneurysms. GastrointestEndosc. 1997;46(6):544-9.

18. Bergert H, Hinterseher I, Kersting S, Leonhardt J, Bloomenthal A, Saeger HD. Management and outcome of hemorrhage due to arterial pseudoaneurysms in pancreatitis. Surgery. 2005;137(3):323-8.

19. El Hamel A, Parc R, Adda G, Bouteloup PY, Huguet C, Malafosse M. Bleeding pseudocysts and pseudoaneurysms in chronic pancreatitis. Br J Surg. 1991;78(9):1059-63.

20. Gambiez LP, Ernst OJ, Merlier OA, Porte HL, Chambon JPM, Quandalle PA. Arterial Embolization 
for Bleeding Pseudocysts Complicating Chronic Pancreatitis. Arch Surg. 1997;132(9):1016-21.

21. Boudghène F, L'Herminé C, Bigot JM. Arterial complications of pancreatitis: diagnostic and therapeutic aspects in 104 cases. J Vasc Interv Radiol JVIR. 1993;4(4):551-8.

22. Koo BC, Chinogureyi A, Shaw AS. Imaging acute pancreatitis. Br J Radiol. 2010;83(986):104-12.

23. Shyu JY, Sainani NI, Sahni VA, Chick JF, Chauhan NR, Conwell DL et al. Necrotizing pancreatitis: diagnosis, imaging, and intervention. Radiogr Rev PublRadiol Soc N Am Inc. 2014;34(5):1218-39.

24. Banks PA, Freeman ML, Practice Parameters Committee of the American College of Gastroenterology. Practice guidelines in acute pancreatitis. Am J Gastroenterol. 2006;101(10):2379-400.
25. De Perrot M, Berney T, Bühler L, Delgadillo X, Mentha G, Morel P. Management of bleeding pseudoaneurysms in patients with pancreatitis. $\mathrm{Br} \mathbf{J}$ Surg. 2003;86(1):29-32.

26. Hsu J-T, Yeh C-N, Hung C-F, Chen H-M, Hwang TL, Jan Y-Y et al. Management and outcome of bleeding pseudoaneurysm associated with chronic pancreatitis. BMC Gastroenterol. 2006;6:3.

Cite this article as: Bagwan AI, Chidambaram K, Sankareswaran S, Raju P, Chidambaranathan S, Lakshamanamoorthy NBO. Management of visceral arterial pseudoaneurysms in patients with acute and chronic pancreatitis: a retrospective study from South Indian tertiary care centre. Int Surg J 2021;8:2980-7. 